\title{
Nonhost Resistance of Arabidopsis thaliana Against Alternaria alternata Involves both Pre- and Postinvasive Defenses but Is Collapsed by AAL-Toxin in the Absence of $\mathrm{LOH} 2$
}

\author{
Mayumi Egusa, Takuya Miwa, Hironori Kaminaka, Yoshitaka Takano, and Motoichiro Kodama
}

First and fifth authors: Laboratory of Plant Pathology, and second and third authors: Laboratory of Plant Molecular Biology, Faculty of Agriculture, Tottori University, 4-101 Koyama-Minami, Tottori 680-8553, Japan; and fourth author: Department of Plant-Microbe Interactions, Graduate School of Agriculture, Kyoto University, Kyoto 606-8502, Japan.

Accepted for publication 11 January 2013.

\begin{abstract}
Egusa, M., Miwa, T., Kaminaka, H., Takano, Y., and Kodama, M. 2013. Nonhost resistance of Arabidopsis thaliana against Alternaria alternata involves both pre- and postinvasive defenses but is collapsed by AALtoxin in the absence of $\mathrm{LOH} 2$. Phytopathology 103:733-740.

The tomato pathotype of Alternaria alternata causes Alternaria stem canker on tomato depending upon the production of the host-specific AAL-toxin. Host defense mechanisms to A. alternata, however, are largely unknown. Here, we elucidate some of the mechanisms of nonhost resistance to A. alternata using Arabidopsis mutants. Wild-type Arabidopsis showed either no symptoms or a hypersensitive reaction (HR) when inoculated with both strains of AAL-toxin-producing and nonproducing A. alternata. Yet, when these Arabidopsis penetration (pen)

mutants, pen 2 and pen 3 , were challenged with both strains of A. alternata, fungal penetration was possible. However, further fungal development and conidiation were limited on these pen mutants by postinvasion defense with HR-like cell death. Meanwhile, only AAL-toxin-producing A. alternata could invade lag one homologue (loh 2 mutants, which have a defect in the AAL-toxin resistance gene, subsequently allowing the fungus to complete its life cycle. Thus, the nonhost resistance of Arabidopsis thaliana to A. alternata consists of multilayered defense systems that include pre-invasion resistance via PEN2 and PEN3 and postinvasion resistance. However, our study also indicates that the pathogen is able to completely overcome the multilayered nonhost resistance if the plant is sensitive to the AAL-toxin, which is an effector of the toxin-dependent necrotrophic pathogen A. alternata.
\end{abstract}

Plants are continuously threatened by a large number of potentially pathogenic microbes that exhibit different lifestyles. Nevertheless, most plants are resistant to the majority of potential pathogens and susceptible to only a small number of adapted microbes. The term "nonhost resistance" is defined such that entire plant species must exhibit resistance to all genetic variants of a nonadapted pathogen species $(25,27,29)$. Nonhost resistance is a consequence of multilayered defense mechanisms that include both constitutive barriers and inducible reactions $(25,27$, 29). It is widely acknowledged that not only nonhost but also basal resistance mechanisms are elicited by recognition of nonself molecules, microbe-associated molecular patterns (MAMPs), or pathogen-associated molecular patterns $(18,25,27,29)$. Certain successful pathogens that have evolved effectors can invade plants by interference of MAMP-triggered immunity, which is known as effector-triggered susceptibility. Subsequently, some plants enhance defense systems which are evoked by the recognition of effectors. This sequential co-evolution between plants and microbes and MAMP- or effector-triggered immunity and susceptibility forms the concept of plant immunity $(18,27)$.

Several studies have been conducted on nonhost resistance. It is well known that Arabidopsis PENETRATION (PEN) mutants fail to defend against entry of nonadapted powdery mildews $(6,22$, 33). PEN1 encodes SYP121 (syntaxin of plants 121), a plasma membrane-resident syntaxin with a soluble N-ethylmaleimide-

Corresponding author: M. Kodama; E-mail address: mk@muses.tottori-u.ac.jp

* The $e$-Xtra logo stands for "electronic extra" and indicates that the online version contains three supplemental figures. Figures 1, 2, 4, and 5 appear in color online.

http://dx.doi.org/10.1094/PHYTO-08-12-0201-R

(C) 2013 The American Phytopathological Society sensitive factor attachment protein receptor (SNARE) domain (6). SNARE domain-containing proteins play a key role in vesicleassociated membrane fusion and secretion processes, including exocytosis and endocytosis. It is suggested that PEN1 secretes cell wall precursors or antimicrobial compounds at the sites of attempted fungal invasion $(3,21)$. PEN2 encodes a peroxisomeassociated glycosyl hydrolase, an atypical myrosinase that hydrolyzes 4-methoxynidol-3-ylmethylglucosinolates (4MI3G) as an in planta substrate for antifungal responses $(4,22)$. PEN3 encodes a plasma membrane-resident pleiotropic drug resistance ATPbinding cassette (ABC) transporter, PDR8 (33). PEN3 is likely involved in exporting a toxic compound, whose synthesis is catalyzed by PEN2, at attempted fungal entry sites $(3,21,33)$. One mechanism of nonhost resistance conferred by these three genes consists of two distinct secretory pathways, PEN1 or co-operative PEN2 and PEN3 pathways $(3,21)$. PEN1 seems to be engaged exclusively for nonhost resistance against powdery mildews, whereas PEN2 and PEN3 contribute to resistance against these multiple parasites: Colletotrichum gloeosporioides, Magnaporthe grisea, Phakopsora pachyrhizi, Pythium irregular, and Phytophthora infestans $(15,22-24,33)$.

Alternaria alternata (Fr.) Keissl. is a ubiquitous fungus that can be found on many kinds of plants and other substrata all over the world. While having a general potential for aggressiveness, most of them are unable to invade potential host plants due to nonhost or basal resistance $(28,30)$. However, some of them are necrotrophic pathogens that produce host-specific toxins (HSTs) that confer fungal pathogenicity or virulence, leading to necrotic cell death only on susceptible plants. Specifically, HSTs are considered to be primary determinants of pathogenicity (in other words, effectors) that contribute to the establishment of susceptibility by suppression of plant defense responses $(10,28,30)$. 
The tomato pathotype of $A$. alternata, the causal agent of Alternaria stem canker, produces host-specific AAL-toxin $(12,37)$. AAL-toxin causes necrotic cell death on susceptible tomato plants and induces pathogen infection. It has been reported that the target of AAL-toxin is the enzyme sphinganine $\mathrm{N}$-acyltransferase, which contributes to ceramide biosynthesis $(13,32)$. The insensitivity of tomato to AAL-toxin is conferred by the resistance gene Alternaria stem canker gene 1 (Asc-1), a homolog of the yeast longevity assurance gene LAG1 that encodes ceramide synthase, which appears to salvage the endoplasmic reticulum-to-Golgi transportation of glycosylphosphatidylinositol-anchored proteins by the production of an alternative ceramide (5). It has been shown that Arabidopsis thaliana LAG1 homologues (lag one homologue $[L O H] 1,-2$, and 3) are ceramide synthases and contribute to sensitivity or insensitivity to AALtoxin $(11,35)$.

Although the roles for HSTs as effectors which lead to disease susceptibility have been well characterized in some plantpathogen interactions, there is little knowledge on the defense mechanisms in plants. In this study, we have analyzed the nonhost resistance against Alternaria alternata using Arabidopsis as a model system. Here, we demonstrate that PEN2 and PEN3 contribute to nonhost resistance against $A$. alternata. Microscopic analyses indicated that nonhost resistance in Arabidopsis to A. alternata consists of multilayered defense mechanisms that include pre-invasion resistance, including PEN2 and PEN3 and an unknown postinvasion resistance mechanism with a hypersensitive reaction (HR). Notably, the results suggest that the HST could entirely impair the multilayered nonhost resistance systems in the toxin-sensitive plants.

\section{MATERIALS AND METHODS}

Fungal strain and plant material. The tomato pathotype of $A$. alternata (synonym A. alternata f. sp. lycopersici, A. arborescens) strain As-27 which produces host-specific AAL-toxin, and nonpathogenic A. alternata strain O-94 which does not produce AAL-toxin, were maintained on potato dextrose agar (Difco Laboratories, Detroit) slopes or as $15 \%$ glycerol stocks at $-80^{\circ} \mathrm{C}$. The following Arabidopsis lines were used in this study: Columbia (Col-0), pen1-1 (6), pen2-1 (22), pen2-2 (22), and pen3-1 (33). The T-DNA insertion lines in loh2-1 (SALK_018608) and loh2-2 (SALK_024192) were obtained from the Arabidopsis Biological Resource Center (1). Plants were grown in sterilized soil in a growth chamber (Growth Cabinet MLR-350; Sanyo, Osaka, Japan) with a 10 -h photoperiod at $22^{\circ} \mathrm{C}$.

Inoculation. For pathogenicity tests, spores of the fungus were prepared as described previously (17). Droplets $(5 \mu \mathrm{l})$ of spore suspensions $\left(5 \times 10^{5}\right.$ spores $\left./ \mathrm{ml}\right)$ were placed onto the leaf surface. Inoculated plants were incubated in a moist chamber with a 10-h photoperiod at $22^{\circ} \mathrm{C}$ and lesion formation was observed at 7 days postinoculation. Infection behaviors were examined by microscopic observation, as described previously (7).

Microscopic observation. To detect generation of $\mathrm{H}_{2} \mathrm{O}_{2}$ in inoculated leaves, 3,3'-diaminobenzidine (DAB) staining was performed as described by Thordal-Christensen et al. (36). Inoculated leaves were collected after 7 days of inoculation and soaked in a DAB solution ( $1 \mathrm{mg} / \mathrm{ml}, \mathrm{pH} 3.8)$ overnight. Subsequently, leaves were decolorized by ethanol. Ethanol was replaced with chloral hydrate solution (chloral hydrate, $8 \mathrm{~g}$; glycerol, $1 \mathrm{ml}$; and $\mathrm{H}_{2} \mathrm{O}, 2 \mathrm{ml}$ ) and leaves were observed under a light microscope (Nikon, Tokyo). The cell death on inoculated leaves was visualized by trypan blue staining. Inoculated leaves were boiled in a staining solution (lactophenol [lactic acid/glycerol/ phenol/water, 1:1:1:1, by volume]/EtOH, 1:2 [vol/vol] and trypan blue at $2.5 \mathrm{mg} / \mathrm{ml}$ ] for $1 \mathrm{~min}$ and incubated overnight at room temperature. Then, leaf samples were replaced in a chloral hydrate solution and observed with a light microscope. To visual- ize callose deposition, inoculated leaves were fixed and decolorized in ethanol-acetic acid solution $(3: 1$ [vol/vol]) until chlorophyll was removed. The leaves were then stained with aniline blue $(0.1 \%$ [wt/vol] $)$ in $100 \mathrm{mM} \mathrm{K} \mathrm{HPO}_{4}$, $\mathrm{pH} 8.5$ as described by Narusaka et al. (26). Callose deposition was examined under a fluorescent microscope (TE300-FN; Nikon). Fungal growth on inoculated leaves was visualized by histochemical staining using wheat germ agglutinin (WGA) Alexa Fluor 488 conjugate (Invitrogen, Carlsbad, CA). Inoculated leaves were harvested at 7 days postinoculation and soaked into WGA conjugate solution at $5 \mu \mathrm{g} / \mathrm{ml}$ following the manufacturer's instructions. Fungal mycelium was observed under a fluorescent stereomicroscope (VB-G25; Keyence, Osaka, Japan).

Bioassay of AAL-toxin. Excised leaves were treated with different concentrations of the toxin solutions $(0.01,0.1,0.5$, and $1 \mu \mathrm{g} / \mathrm{ml})$ by absorption through petioles. Leaves were incubated at $25^{\circ} \mathrm{C}$ for 4 days under fluorescent light.

Assay for antifungal component from leaves. Drops $(30 \mu \mathrm{l})$ of spore suspensions $\left(10^{6}\right.$ spores $\left./ \mathrm{ml}\right)$ of O-94 were placed on leaves and incubated for $24 \mathrm{~h}$. The suspensions on the leaves were harvested and centrifuged at $16,000 \times g$ for $5 \mathrm{~min}$ to remove germination spores. Spores of O-94 were suspended in the supernatant $\left(5 \times 10^{5}\right.$ spores $\left./ \mathrm{ml}\right)$ and placed on a cellulose membrane (seamless cellulose tubing; Wako Pure Chemicals, Osaka, Japan). After $24 \mathrm{~h}$, spore germination, appressorium formation, and infection hypha formation were observed under a light microscope.

Measurement of conidiation. Ten inoculated leaves were harvested at 10 days postinoculation and shaken vigorously in $1 \mathrm{ml}$ of distilled water containing $0.01 \%$ (vol/vol) Tween 20 . Samples were centrifuged ( $5 \mathrm{~min}$ ) and, then, $700 \mu \mathrm{l}$ of supernatant was discarded. Reproduced-spores were counted by using a hemocytometer.

Fungal biomass determination. Total genomic DNA was prepared from 10 inoculated leaves. Real-time polymerase chain reaction (PCR) was performed as described previously (9) and the primer pairs corresponding to MAT1-1 idiomorph 3' flanking region of A. alternata (2) were used.

Reverse-transcription PCR. To determine expression of $\mathrm{LOH} 2$ in loh2 mutants, total RNA were extracted from plants with the Total RNA Extraction Kit Mini (Plant) (RBC Bioscience, Taipei, Taiwan) following the manufacturer's instructions. Total RNA was treated with DNase I (Takara, Ohtsu, Japan) to remove traces of contaminating DNA and $1 \mu \mathrm{g}$ of RNA was converted into cDNA by the PrimeScript II 1st strand cDNA Synthesis Kit (Takara) according to the manufacturer's conditions. The primer pairs (AtLAG2RT-F, 5'-GTGTATGGTGTGGCTGCGTTG-3' and AtLAG2RT-R, 5'-CATCATCATCCTCTGAATCGG-3') corresponding to $\mathrm{LOH} 2$ were used. As a control for equal cDNA amounts in each reaction, PCR was performed with primers for elongation factor $1 \alpha(E F 1 \alpha)$ (AtEF-1RT-F, 5'-GATGATTTG CTGTTGTAACAAGATG-3' and AtEF-1RT-R 5'-ATACCA CCAATCTTGTAGACATCC-3'). Reverse-transcription (RT)PCR was performed with the following conditions; initial step of $5 \mathrm{~min}$ at $95^{\circ} \mathrm{C}$; followed by 28 cycles for $\mathrm{LOH} 2$ or 24 cycles for $E F 1 \alpha$ of $15 \mathrm{~s}$ at $95^{\circ} \mathrm{C}, 15 \mathrm{~s}$ at $55^{\circ} \mathrm{C}$, and $30 \mathrm{~s}$ at $72^{\circ} \mathrm{C}$; and a final step of $5 \mathrm{~min}$ at $72^{\circ} \mathrm{C}$.

Statistical analysis. Analyses of variance (ANOVAs) for all fungal developments were performed by a one-way ANOVA on Excel and Tukey's test at a significance level of $P<0.05$. Antifungal effect of elucidates from inoculated leaves on spore germination, appressorium formation, and infection hyphae formation were compared by two-way ANOVA $(P<0.05)$ on Excel.

\section{RESULTS}

Nonhost resistance to Alternaria infection was compromised in pen mutants. None of the known A. alternata strains infect 
wild-type Arabidopsis plants and the plant is considered to be a nonhost to A. alternata (26). To assess the components of nonhost resistance to A. alternata, Arabidopsis pen mutants known to be defective in penetration resistance to various parasites were inoculated with the tomato pathotype of A. alternata strain As-27, whose pathogenicity depends on AAL-toxin. Wild-type Col-0 exhibited resistance to As-27 infection regardless of toxin production (Fig. 1A). Microscopic observation revealed that germination tubes were detected on the leaf surface of Col-0 (Supplemental Figure 1) and neither infection hyphae nor an HR concomitant with cell death was detected on Col-0 (Fig. 1A and B). On the other hand, macroscopic lesion formation developed on pen2-1, pen2-2, and pen3-1 mutants inoculated with As-27, and microscopic observation revealed that infection hyphae were found (Fig. 1A and B), whereas pen 1-1 mutants did not develop any symptoms (Fig. 1A). All pen mutants were resistant to AAL-toxin and comparable with Col-0 at an AAL-toxin concentration of $1 \mu \mathrm{g} / \mathrm{ml}$ (Fig. 1C). The same results in fungal infection were observed on pen mutants which were inoculated with nonpathogenic A. alternata strain O-94, which does not produce AALtoxin.

Identification of a highly susceptible Arabidopsis mutant against Alternaria infection. AAL-toxin enables the tomato pathotype of A. alternata to infect susceptible plants with respect to LAG1 homologue deficiency. Previously, Gechev et al. (11) reported that the LAGl homologue knockout mutant Arabidopsis $\mathrm{LOH} 2$ from the Wassilewskija ecotype showed AAL-toxin sensitivity but susceptibility to fungal infection has not investi- gated. To be able to compare the $\mathrm{LOH} 2$ mutants alongside the pen mutants that were derived from Col-0, we searched for $\mathrm{LOH}_{2}$ Col-0-derived mutants in public T-DNA insertion line collections (1). Two T-DNA insertion lines were obtained. Each line, SALK_018608 and SALK_024192, carrying an insertion in the third exon or the first intron, respectively, of $\mathrm{LOH}$, was named loh2-1 and loh2-2 (Fig. 2A). RT-PCR amplification to check for the $L O H 2$ transcript in loh2-1 and loh2-2 could not detect any gene expression in both mutant lines (Fig. 2B). An AAL-toxin sensitivity test revealed that both mutant lines exhibited high sensitivity to AAL-toxin (Fig. 2C). The wild-type Arabidopsis Col-0 was resistant to AAL-toxin and did not show any symptoms at a concentration of $1 \mu \mathrm{g} / \mathrm{ml}$ (Fig. 2C). On the other hand, chlorotic cell death on both loh2-1 and loh2-2 mutants appeared at a low AAL-toxin concentration $(0.1 \mu \mathrm{g} / \mathrm{ml})$ and severity of cell death was dose dependent (Fig. 2C). The level of sensitivity to AAL-toxin in these mutants was comparable with the susceptible (asc/asc) tomato genotype $(9,37,38)$. In addition to toxin sensitivity, both loh2 mutants allowed fungal infection. Inoculation with As-27 to loh2 mutants showed severe disease symptoms accompanied by necrotic cell death, and infection hyphae were observed (Fig. 2D and E). Meanwhile, nonpathogenic $A$. alternata strain $\mathrm{O}-94$ failed to invade $l o h$ mutants.

Fungal biomass and conidiation. To assess fungal progression, fungal penetration, biomass, and conidiation were determined. Although there were no differences in spore germination among Col-0 and Arabidopsis mutants, infection hyphae formation differed. Both strains of A. alternata failed to penetrate
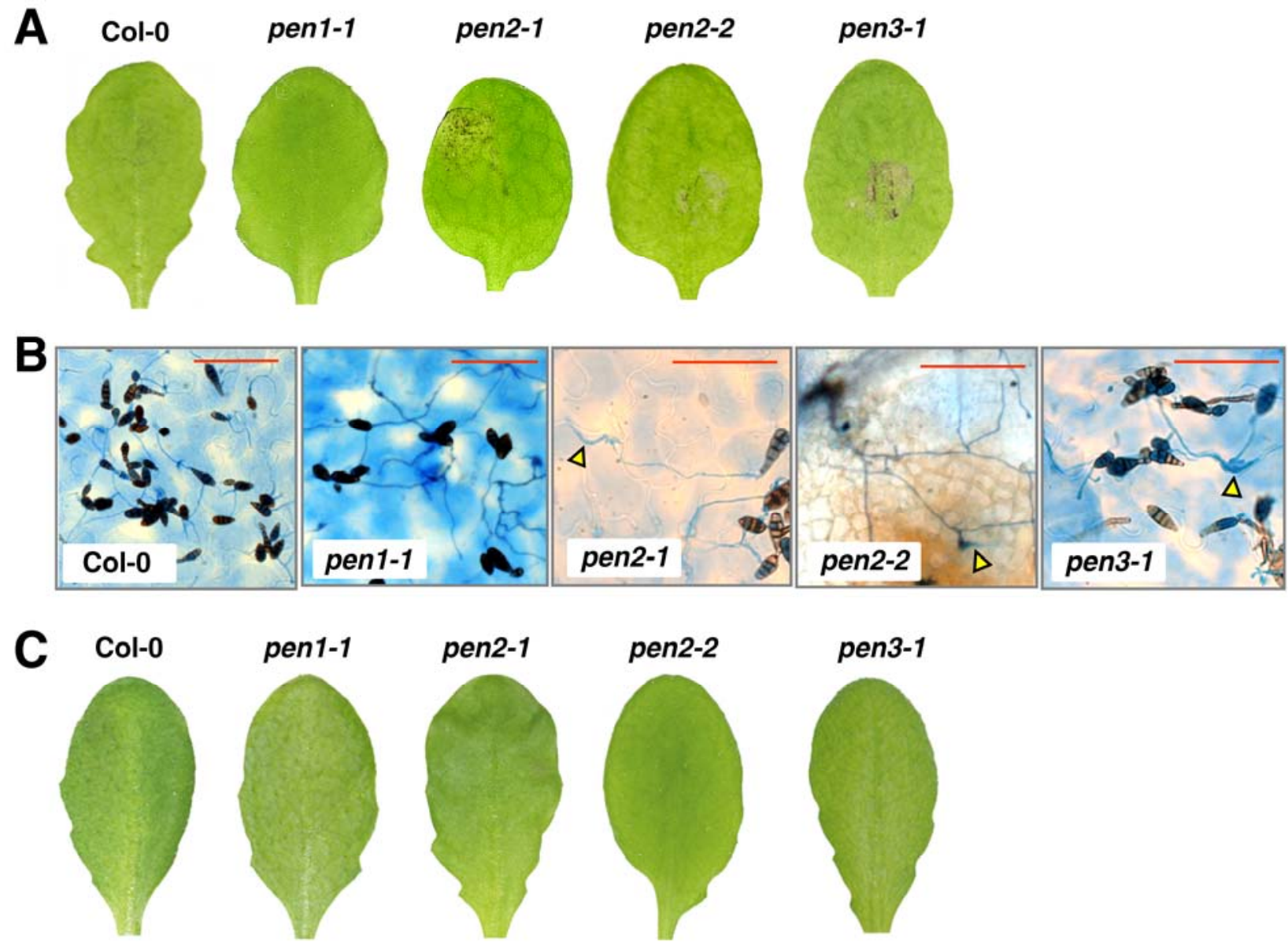

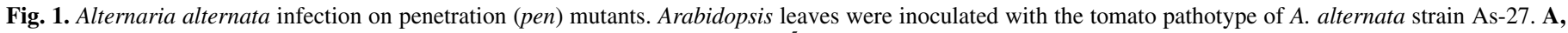

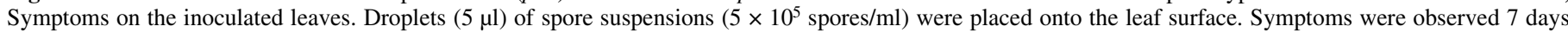

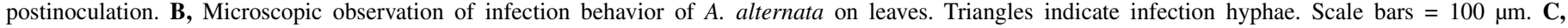

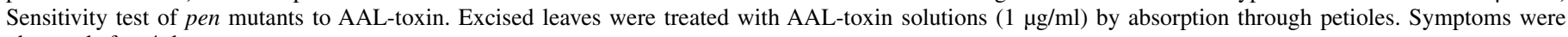
observed after 4 days. 
Col-0 and rates of infection hyphae formation on pen 1-1 mutants were comparable with Col-0 (Fig. 3; Supplemental Figure 2). On the other hand, fungal infection hyphae formation increased to $\approx 10 \%$ on pen $2-1$, pen $2-2$, and pen3-1 mutants and there were no differences in the rate of infection hyphae formation of both stains among pen 2 and pen 3 mutants (Fig. 3). Numerous infection hyphae were detected and $\approx 30$ and $48 \%$ of As-27 succeeded in penetration into loh2-1 and loh2-2 mutants, respectively (Fig. 3). Following penetration, mycelial growth was detected by the Alexa Fluor 488 conjugate of WGA, which exhibits green fluorescence when binding to $N$-acetylglucosaminyl residues of fungal cell wall component. Despite spore germination of As-27 observed on Col-0, green fluorescence was not detected because fungal growth and expansion were not sufficient for fluorescence staining (Fig. 4A). On the other hand, remarkable fluorescence was observed in the combination of As-27 and loh mutants, and fungal mycelium expanded on the leaf (Fig. 4A). Although the level of toxin sensitivity of both loh2 mutants was similar, the level of susceptibility to the pathogen was not the same. These results indicate that the truncated form of Asc-1 might have a
A

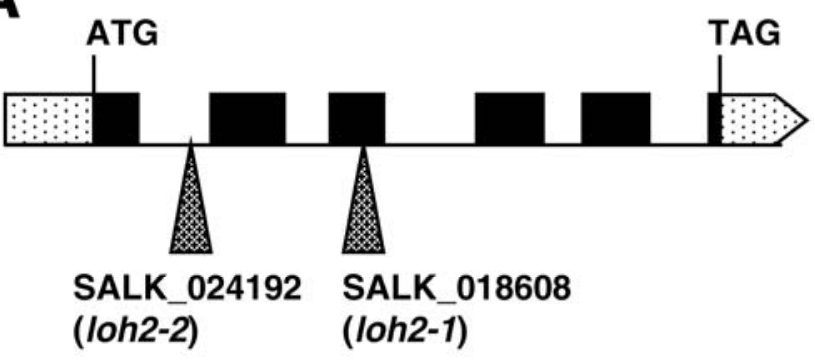

B

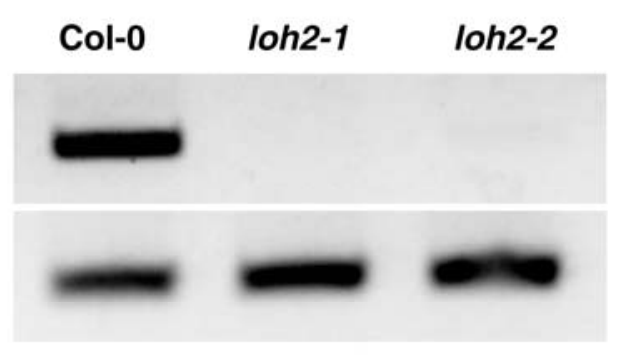

$\mathrm{LOH} 2$

EF1a

C

AAL-toxin $\mathrm{T}_{\mathrm{A}}(\mu \mathrm{g} / \mathrm{mL})$
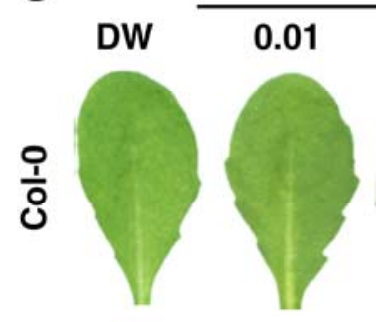

\begin{abstract}
0.1
\end{abstract}

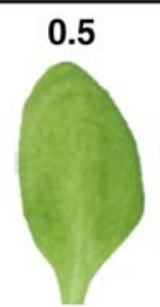

1
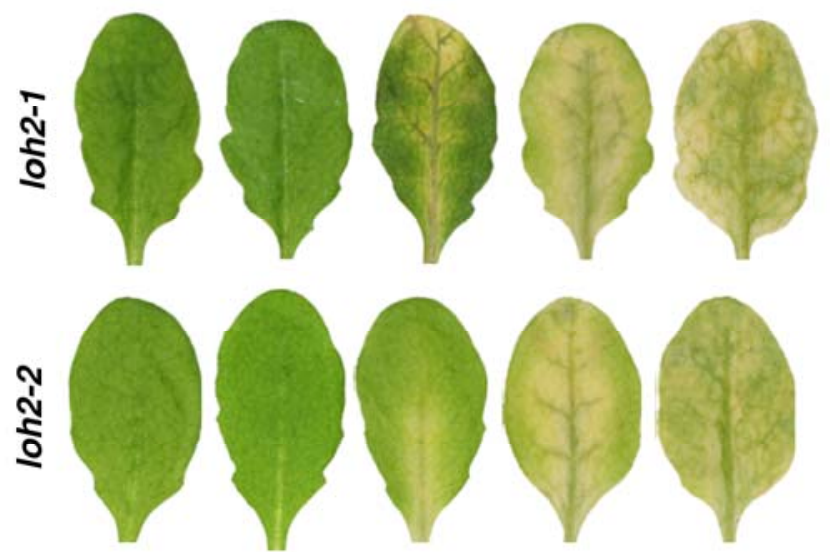
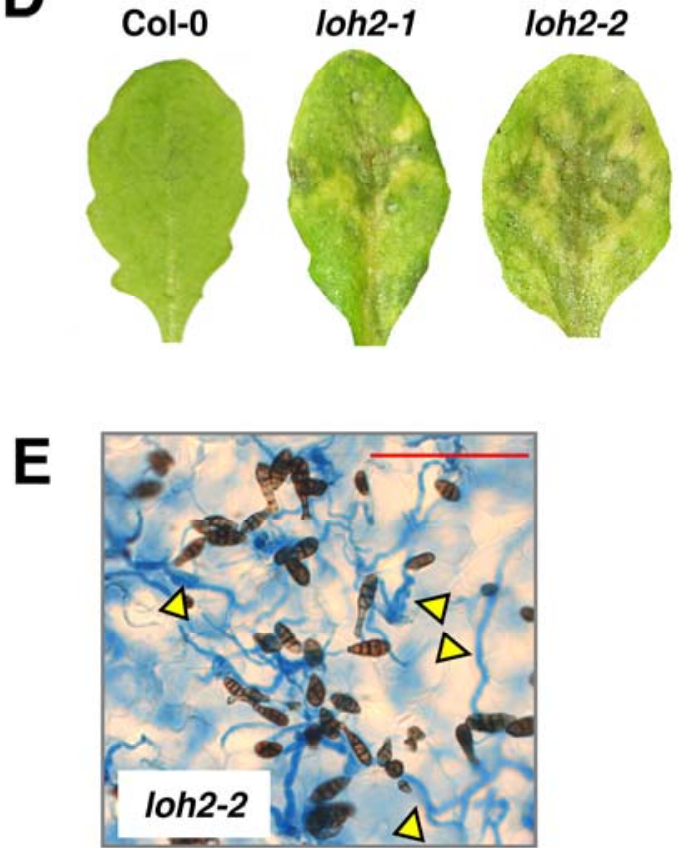

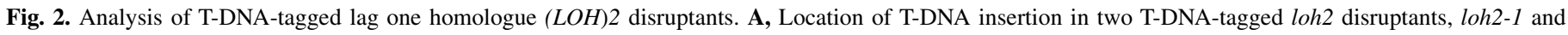

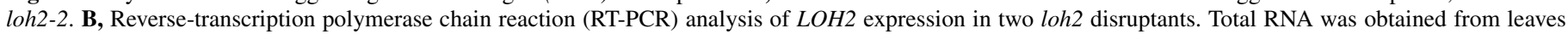

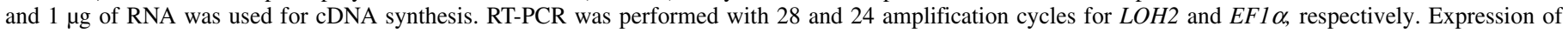

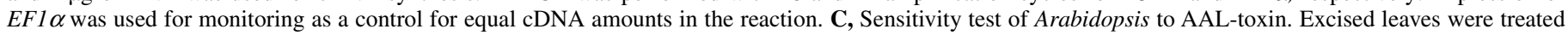

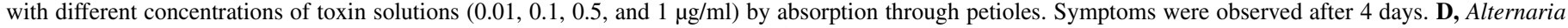

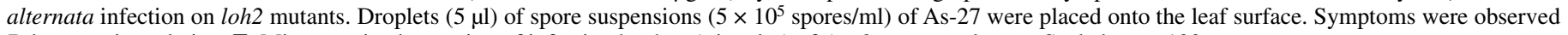
7 days postinoculation. E, Microscopic observation of infection hyphae (triangles) of A. alternata on leaves. Scale bars $=100 \mu$ m. 
dominant negative-like effect. In contrast, fungal penetration was detected on pen2-1, pen2-2, and pen3-1 mutants but green fluorescence was not detected because fungal growth and expansion were not sufficient for fluorescence staining, the same as the result on Col-0 (Fig. 4A). No green fluorescence was observed on Col-0 and mutants inoculated with O-94. The amount of fungal DNA in inoculated leaves was determined by real-time PCR using A. alternata mating-type gene-specific primers. Both loh 2 mutants showed that the fungal biomass of As27 in inoculated leaves was greater than other combinations (Fig. 4B). In spite of infection hyphae formation, fungal biomass levels on pen mutants were at the same level as on Col-0 (Fig. 4B). There were no differences in fungal biomass among Col-0 and mutants inoculated with O-94. In addition to fungal expansion, conidiation that occurs in a compatible interaction at the final stage of fungal infection was estimated. There were no differences among pen mutants and Col-0 inoculated with both strain of A. alternata (Fig. 4C), whereas significant conidiation was observed on loh2-1 and loh2-2 mutants inoculated with As-27 (Fig. 4C). The loh 2 mutation led to full infection and enabled completion of the life cycle of the As-27, and their interaction is regarded as a compatible interaction. These result indicated that pen mutants were compromised only in pre-invasion resistance and that postinvasion resistance against fungal development was still active.

HR-like cell death and $\mathrm{H}_{2} \mathrm{O}_{2}$ accumulation. There are two types of nonhost resistance: one of them is associated with HR cell death and the other shows no visible symptoms (25). According to Narusaka et al. (26), nonhost resistance of Arabidopsis to A. alternata was not accompanied by HR-like cell death. Likewise, trypan blue staining revealed that cell death was not detected on Col-0 inoculated with As-27 (Fig. 5A). DAB staining was performed to detect the generation of $\mathrm{H}_{2} \mathrm{O}_{2}$ that was associated with $\mathrm{HR} . \mathrm{H}_{2} \mathrm{O}_{2}$ generation was not observed on Col-0 (Fig. 5B). Similarly, neither cell death nor $\mathrm{H}_{2} \mathrm{O}_{2}$ were detected in the pen 1-1 mutant inoculated with As-27 (Fig. 5A and B). In contrast, inoculation with As-27 on the pen2-1, pen2-2, and pen31 mutants induced an HR-like cell death concomitant with $\mathrm{H}_{2} \mathrm{O}_{2}$ generation (Fig. 5A and B). When both loh2 mutants were challenged with As-27, HR-like cell death and $\mathrm{H}_{2} \mathrm{O}_{2}$ accumulation were extensively detected (Fig. 5A and B). HR-cell death and $\mathrm{H}_{2} \mathrm{O}_{2}$ accumulation were observed on only pen 2 and pen 3 mutants inoculated with O-94 (Supplemental Figure 3).

Callose deposition. There are many reports on the role of formation of cell wall apposition or papillae in nonhost resistance (14); therefore, callose deposition, which is a major component of cell wall apposition, was evaluated. It has been reported that callose deposition was observed in Col-0 inoculated with $A$. alternata less than with A. brassicicola (26). Similarly, we detected slight callose deposition on Col-0 inoculated with As-27 (Fig. 5C). The degree of callose deposition on pen1-1 mutants was comparable with Col-0 (Fig. 5C). By contrast, the number and size of cells with callose deposition were enlarged on pen2-1, pen2-2, and pen3-1 mutants (Fig. 5C), similar to A. brassicicolachallenged Col-0 (26). Enormous callose deposition was detected on loh 2 mutants by inoculation with As-27 (Fig. 5C). Moderate callose deposition was observed on pen 2 and pen 3 mutants but not on loh mutants inoculated with O-94.

Antifungal activity of exudates from inoculated leaves. Previously, the role of $\mathrm{ABC}$ transporters as pumps for the release of antifungal compounds has been revealed in Nicotiana spp. (16). PEN3 is assumed to release antimicrobial compounds at the site of attempted fungal invasion $(3,22)$. Therefore, we assessed the induction of antifungal compounds from inoculated leaves. Spores of O-94 were suspended in exudates which were collected from inoculated leaf surfaces, and spore germination, appressorium formation, and infection hyphae formation was assessed by microscopic observation. No differences in spore germination and appressorium formation among the exudates from Col-0 and pen mutants were detected (Fig. 6). Furthermore, rate of infection hyphae formation was also similar among all plants (Fig. 6). These results suggest that antimicrobial compounds might not be released to the surface on Arabidopsis leaves during A. alternata infection.

\section{DISCUSSION}

The nonhost resistance of Arabidopsis to A. alternata has been described by Narusaka et al. (26). Likewise, we observed a nonhost resistance reaction to A. alternata infection in wild-type Arabidopsis Col-0, and this was represented as a failure to form lesions, fungal penetration, fungal progression, and conidiation. There are two types of nonhost resistance: one of them is associated with HR cell death and the other type produces no visible symptoms (25). Neither cell death nor infection hyphae were detected in the interaction between A. alternata and Col-0. In the infection process of A. alternata, formation of the infection hypha is the most critical step in initial establishment of successful invasion $(7,28,30)$. We obtained the $\mathrm{LOH} 2$ knockout mutants loh2-1 and loh2-2 in Col-0 and showed not only AAL-toxin sensitivity but also pathogen susceptibility. The sensitivity and susceptibility levels of both loh2 mutants were similar to the susceptible host tomato genotype $(9,37,38)$. Furthermore, the tomato pathotype of $A$. alternata markedly proliferated on both loh 2 mutants leaves and conidiation was found at a later stage of infection. The loh 2 mutants allowed the tomato pathotype of $A$. alternata not only to penetrate but also to complete its life cycle. In contrast, successful penetration was not observed in the combination of non-toxin-producing strain O-94/loh2 mutants or toxin-producing strain As-27/wild-type Col-0. It was reported that induced resistance in host tomato plants by nonpathogenic O-94 was defeated by AAL-toxin treatment $(7,38)$. The critical role of HSTs was considered to suppress the induction of general resistance specifically in susceptible plant (30). These results indicate that the interaction between loh 2 mutants and the tomato pathotype of $A$. alternata leads to full compatibility as a consequence of toxin sensitivity of Arabidopsis and AAL-toxin productivity of the pathogen.

Arabidopsis pen mutants have been well studied and shown to display a reduction in nonhost resistance not only to nonadapted

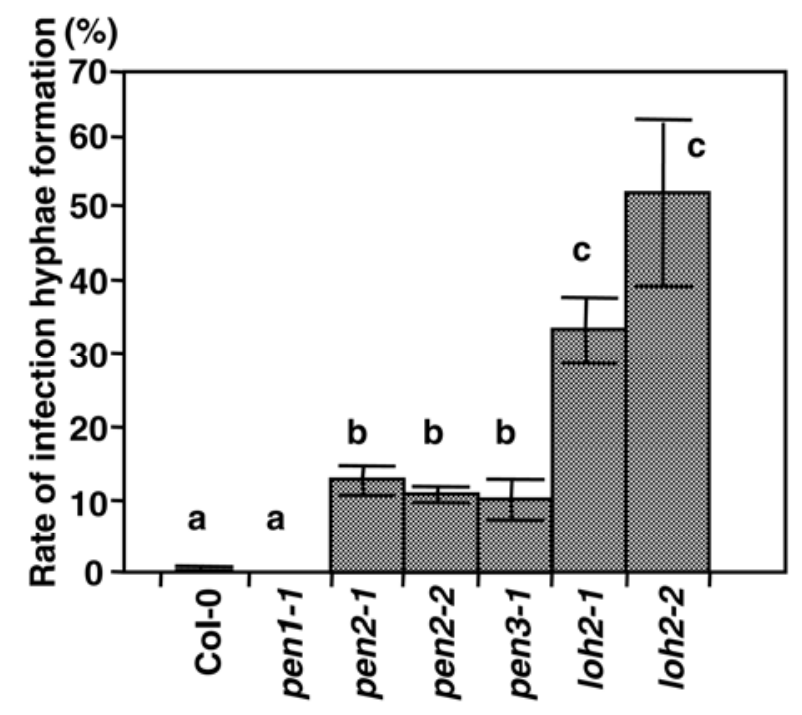

Fig. 3. Penetration ability of the tomato pathotype of Alternaria alternata strain As-27 on Arabidopsis. Microscopic observation of rate of infection hyphae formation on inoculated leaves at 7 days postinoculation. Data represent the mean of five independent experiments and error bars. Means with the same letter are not significantly different according to Tukey's test $(P<0.05)$. 
powdery mildew but also to several parasites $(15,22-24,33)$. In Arabidopsis, PEN1 seems to be engaged exclusively in nonhost resistance against powdery mildews, whereas PEN2 and PEN3 contribute to multiple nonhost pathogen resistance $(15,22-24,33)$.
Similarly, our results show that only pen 2 and pen 3 mutants but not the penl mutant resulted in infection of A. alternata. Although many studies have identified a large number of candidate defense genes involved in the processes of nonhost, basal, or
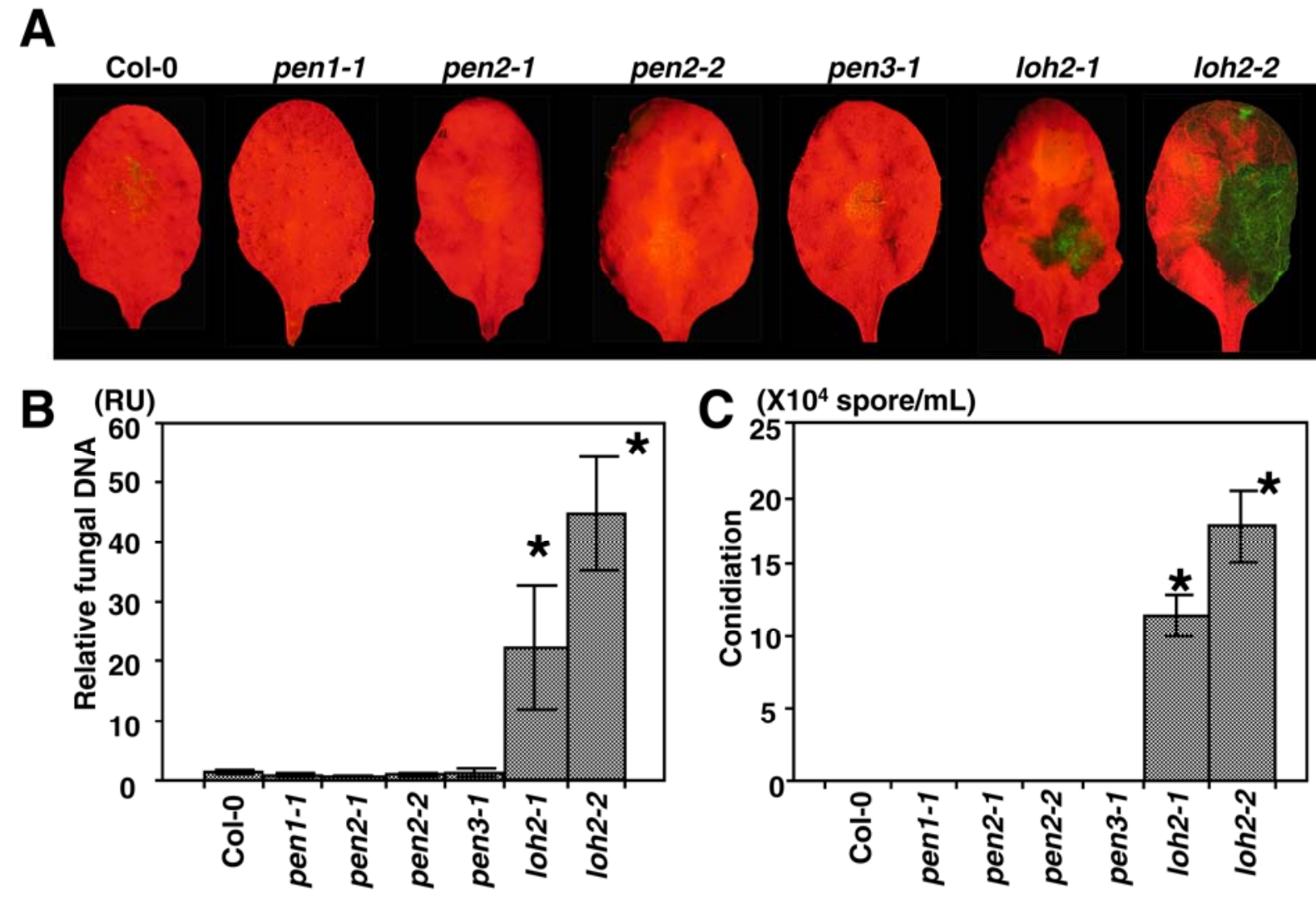

Fig. 4. Disease severity in Arabidopsis mutants inoculated with Alternaria alternata strain As-27. A, Fungal growth on the leaves. Fungal mycelia were stained with wheat germ agglutinin Alexa Fluor 488 conjugate. The blight red color of chlorophyll autofluorescence shows healthy leaf tissue and green color shows fungal mycelia. B, Comparison of fungal growth in Arabidopsis leaves inoculated with As-27 at 7 days postinoculation. Fungal biomass in the infected plants was estimated by quantifying fungal DNAs with real-time polymerase chain reaction using specific primers for the MAT1-1 gene. The result shows relative values to inoculated Col-0 leaves for three independent experiments and error bars. An asterisk indicated significant difference according to Tukey's test $(P<0.05)$. C, Comparison of conidiation of A. alternata strain As-27 on inoculated leaves at 10 days postinoculation. Reproducing spores were harvested from 10 inoculated leaves and determined by using a hemocytometer. Data represent the mean of eight independent experiments and error bars. An asterisk indicated significant difference according to Tukey's test $(P<0.05)$.

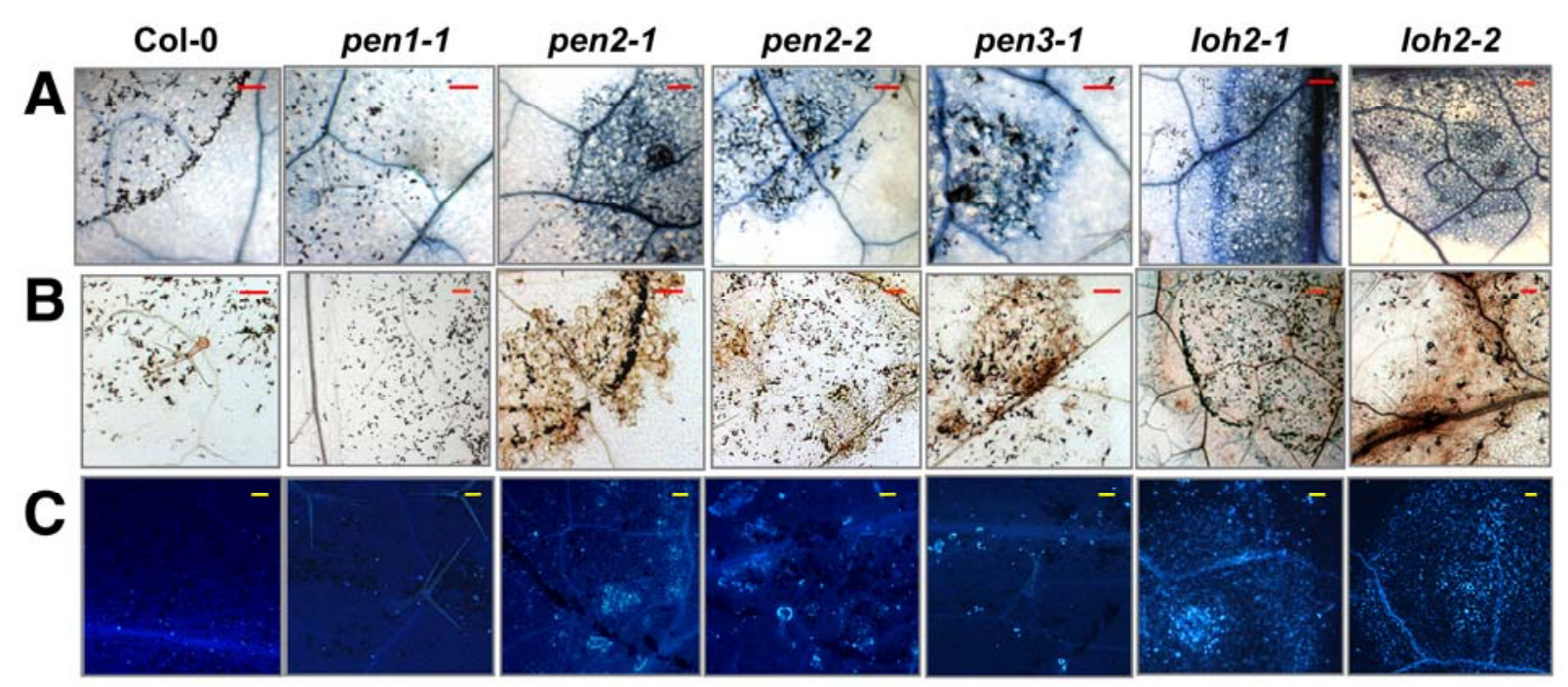

Fig. 5. Hypersensitive reaction events on Arabidopsis mutants. Arabidopsis leaves were inoculated with Alternaria alternata strain As-27 and microscopic observation was conducted at 7 days postinoculation. A, Visualization of cell death by trypan blue staining. B, Detection of $\mathrm{H}_{2} \mathrm{O}_{2}$ generation by $3,3^{\prime}-$ diaminobenzidine staining. $\mathbf{C}$, Detection of callose deposition by fluorescence microscopy following aniline blue staining. Scale bars $=100 \mu \mathrm{m}$. 
general resistant to A. alternata, which consists of sequential multilayered defense mechanisms, the components of resistance have not been previously identified $(7,8,28)$. In fact, expression of the PEN3 gene was increased after A. alternata infection (26). This is the first report to identify a component of nonhost resistance to A. alternata. Meanwhile, the rate of A. alternata penetration on compatible loh2 mutants was higher than on pen mutants, suggesting that the presence of other defense mechanisms for fungal penetration are still active against $A$. alternata in these pen mutants.

The roles of PEN2 and PEN3 are known, with PEN2 described as an atypical myrosinase that hydrolyzes $4 \mathrm{MI} 3 \mathrm{G}$ derived from tryptophan, and PEN3 determined to be an ABC transporter that functions to discharge the PEN2 product into the apoplastic space at the site of attempted fungal invasion $(4,22)$. In addition to PEN3, an ABC transporter of Nicotiana spp. has been demonstrated to have a role as a pump for the release of antifungal compounds (16). We have evaluated the presence of toxic compounds in nonhost resistance of Arabidopsis against $A$. alternata but no antifungal activity was detected. In addition to the PEN2 products, camalexin, an Arabidopsis phytoalexin, which is also derived from tryptophan, has been well characterized for its role for defense against necrotrophic pathogens $A$. brassicicola and Botrytis cinerea (20). However, because nonhost resistance in camalexin-null mutant pad3-1 was not altered by $A$. alternata infection (26), it is suggested that camalexin is not involved in Arabidopsis penetration resistance to A. alternata. The infection-inhibiting factor which represses only infection hypha formation of A. alternata without antifungal effect has been identified from Japanese pear leaves (19). Involvement of such infection-inhibiting factors in nonhost resistance of Arabidopsis against infection with A. alternata needs to be further investigated.

Some studies have demonstrated that nonadapted pathogens succeeded in penetrating into Arabidopsis pen mutant cells but the full life cycle of the pathogen was not completed owing to effective postinvasion resistance associated with HR $(22,24,33)$. Similarly, penetration of A. alternata on pen 2 and pen 3 mutants was concomitant with an HR-like cell death, $\mathrm{H}_{2} \mathrm{O}_{2}$ generation, and callose deposition following fungal development, such that the fungus was unable to complete its life cycle. In addition, $\mathrm{H}_{2} \mathrm{O}_{2}$ generation and callose deposition were extensively detected on Arabidopsis infected with the incompatible pathogen A. brassicicola; however, they were rarely observed by nonhost pathogen A. alternata infection (26). These results indicate that $\mathrm{H}_{2} \mathrm{O}_{2}$ generation and callose deposition was elicited by fungal penetration or, in other words, by the breakdown of pre-invasion resistance. Thus, HR and related events are considered to be part of postinvasion resistance to A. alternata. On the other hand, there have been several studies carried out using cytological analysis of host and nonhost plants during A. alternata infection $(26,31,34)$. These studies have revealed that $\mathrm{H}_{2} \mathrm{O}_{2}$ generation and callose deposition were more distinct on the susceptible Japanese pear leaves than resistant leaves after pathogen penetration concomitant with cell wall and plasma membrane damage $(31,34)$. Moreover, there was a report that $\mathrm{H}_{2} \mathrm{O}_{2}$ generation and cell death were induced in the loh2 mutant by AAL-toxin treatment (11). The cell death in AAL-toxin-sensitive host plants induced by the toxin is a programed cell death similar to the HR-type cell death in incompatible interactions (13). Those results suggested that "HR-like" cell death could be induced in both incompatible and compatible interactions even though the outcome of the cell death events is completely different pathologically. Further study will be necessary to fully understand the pathological roles of the cell death events induced in resistant pen and susceptible loh2 mutants.

The HR symptoms observed on the pen mutants during $A$. alternata infection were similar to those observed on the in- compatible Col-0 during A. brassicicola infection (26). Therefore, we can surmise that the nonhost interaction between Arabidopsis and $A$. alternata may advance in an incompatible interaction if there is a defect in $P E N$ gene functions. In the interaction between Arabidopsis and A. brassicicola, it is well known that the jasmonic acid (JA) signaling pathway is involved in postinvasion resistance. Previously, we have reported that salicylic acid (SA) and JA signaling pathways are not important for induced resistance (in particular, pre-invasion resistance) in host plants to A. alternata $(7,8)$. However, there were some reports that SA or JA signaling mutants with pen mutation differed from pen single mutants in responses to fungal postinvasion $(23,33)$. Therefore, for future research, it should be very interesting to follow up postinvasion resistant mechanisms and explore the role of plant hormonal signaling in resistance to A. alternata.

In summary, we demonstrated that defense activation against $A$. alternata consists of multiple defense mechanisms that use preinvasion resistance which involves PEN2 and PEN3 genes, as well as an unknown postinvasion resistance mechanism. In the nonhost interaction, A. alternata may only have to overcome one or two PEN genes to penetrate Arabidopsis leaves. However, postinvasion resistances which include an HR response effectively inhibit further fungal development. The finding suggests that $A$. alternata must overcome sequential multilayered defense mechanisms to establish compatible interactions on host plants. However, if such nonhost plants become sensitive to AAL-toxin, the toxin-producing pathogen can establish fully compatible interactions with the plant via the toxin-dependent interference of the resistance.

\section{ACKNOWLEDGMENTS}

This work was supported by a Grant-in-Aid for Scientific Research (B) (20380028 and 23380025) from the Japanese Society for Promotion of Sciences and Global COE Program Advanced Utilization of Fungus/ Mushroom Resources for Sustainable Society in Harmony with Nature), MEXT, Japan. We thank L. J. Johnson and R. D. Johnson for valuable suggestions and critical reading of the manuscript, P. Schulze-Lefert for providing the seed of pen 2 lines, S. Somerville for pen3, and D. G. Gilchrist and T. L. Peever for providing the fungal strains.

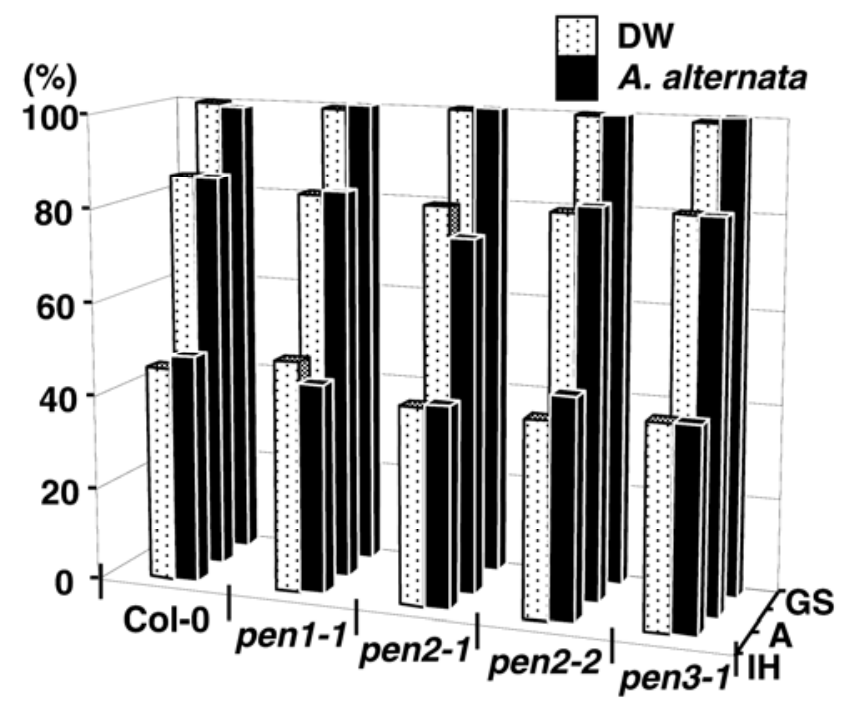

Fig. 6. Antifungal activity test of exudates from leaf surfaces. Exudates were obtained after $24 \mathrm{~h}$ from leaf surfaces challenged by distilled water (DW) (dotted bar) or Alternaria alternata (black bar). Spores of A. alternata suspended in exudates and spore germination (GS), appressorium formation (A), and infection hyphae formation (IH) on cellulose membrane were determined after $24 \mathrm{~h}$. Data represent the mean of four independent experiments. There were no significant differences among plants according to two-way analysis of variance $(P<0.05)$. 


\section{LITERATURE CITED}

1. Alonso, J. M. Stepanova, A. N., Leisse, T. J., Kim, C. J., Chen, H., Shinn, P., Stevenson, D. K., Zimmerman, J., Barajas, P., Cheuk, R., Gadrinab, C., Heller, C., Jeske, A., Koesema, E., Meyers, C. C., Parker, H., Prednis, L., Ansari, Y., Choy, N., Deen, H., Geralt, M., Hazari, N., Hom, E., Karnes, M., Mulholland, C., Ndubaku, R., Schmidt, I., Guzman, P., AguilarHenonin, L., Schmid, M., Weigel, D., Carter, D. E., Marchand, T., Risseeuw, E., Brogden, D., Zeko, A., Crosby, W. L., Berry, C. C., and Ecker, J. R. 2003. Genome-wide insertional mutagenesis of Arabidopsis thaliana. Science 301:653-657.

2. Arie, T., Kaneko, I., Yoshida, T., Noguchi, M., Nomura, Y., and Yamaguchi, I. 2000. Mating-type genes from asexual phytopathogenic ascomycetes Fusarium oxysporum and Alternaria alternata. Mol. PlantMicrobe Interact. 13:1330-1339.

3. Bednarek, P., Kwon, C., and Schulze-Lefert, P. 2010. Not a peripheral issue: secretion in plant-microbe interactions. Curr. Opin. Plant Biol. 13:378-387.

4. Bednarek, P., Pislewska-Bednarek, M., Svatos, A., Schneider, B., Doubsky, J., Mansurova, M., Humphry, M., Consonni, C., Panstruga, R., Sanchez-Vallet, A., Molina, A., and Schulze-Lefert, P. 2009. A glucosinolate metabolism pathway in living plant cells mediates broad-spectrum antifungal defense. Science 323:101-106.

5. Brandwagt, B. F., Mesbah, L. A., Takken, F. L. W., Laurent, P. L., Kneppers, T. J. A., Hille, J., and Nijlamp, H. J. J. 2000. A longevity assurance gene homolog of tomato mediates resistance to Alternaria alternata f. sp. lycopersici toxins and fumonisin B1. Proc. Natl. Acad. Sci. USA 97:4961-4966.

6. Collins, N. C., Thordal-Christensen, H., Lipka, V., Bau, S., Kombrink, E., Qiu, J.-L., Huckelhoven, R., Stein, M., Freialdenhoven, A., Somerville, S. C., and Schulze-Lefert, P. 2003. SNARE-protein-mediated disease resistance at the plant cell wall. Nature 425:973-977.

7. Egusa, M., Akamatsu, H., Tsuge, T., Otani, H., and Kodama, M. 2009. Induced resistance in tomato plants to the toxin-dependent necrotrophic pathogen Alternaria alternata. Physiol. Mol. Plant Pathol. 73: 67-77.

8. Egusa, M., Ochi, H., Tsuge, T., Otani, H., and Kodama, M. 2009. Identification of putative defense-related genes in Japanese pear against Alternaria alternata infection using suppression subtractive hybridization and expression analysis. J. Gen. Plant Pathol. 75:119-124.

9. Egusa, M., Ozawa, R., Takabayashi, J., Otani, H., and Kodama, M. 2009. The jasmonate signaling pathway in tomato regulates susceptibility to a toxin-dependent necrotrophic pathogen. Planta 229:965-976.

10. Friesen, T. L., Faris, J. D., Solomon, P. S., and Oliver, R. P. 2008. Hostspecific toxins: Effectors of necrotrophic pathogenicity. Cell. Microbiol. 10:1421-1428.

11. Gechev, T. S., Gadjev, I. Z., and Hille, J. 2004. An extensive microarray analysis of AAL-toxin-induced cell death in Arabidopsis thaliana brings new insights into the complexity of programmed cell death in plants. Cell. Mol. Life Sci. 61:1185-1197.

12. Gilchrist, D. G., and Grogan, R. G. 1976. Production and nature of a hostspecific toxin from Alternaria alternata f. sp. lycopersici. Phytopathology 66:165-171.

13. Gilchrist, D. G., Wang, H., and Bostock, R. M. 1995. Sphingosine-related mycotoxins in plant and animal disease. Can. J. Bot. 73:S459-S467.

14. Hardham, A. R., Jones, D. A., and Takemoto, D. 2007. Cytoskeleton and cell wall function in penetration resistance. Curr. Opin. Plant Biol. 10:342-348.

15. Hiruma, K., Onozawa-Komori, M., Takahashi, F., Asakura, M., Bednarek, P., Okuno, T., Schulze-Lefert, P., and Takano, Y. 2010. Entry modedependent function of an indole glucosinolate pathway in Arabidopsis for nonhost resistance against anthracnose pathogens. Plant Cell 22:24292443.

16. Jasinski, M., Stukkens, Y., Degand, H., Purnelle, B., Marchand-Brynaert, J., and Boutry, M. 2001. A plant plasma membrane ATP binding cassettetype transporter is involved in antifungal terpenoid secretion. Plant Cell 13:1095-1107.

17. Johnson, R. D., Johnson, L., Itoh, Y., Kodama, M., Otani, H., and Kohmoto, K. 2000. Cloning and characterization of a cyclic peptide synthetase gene from Alternaria alternata apple pathotype whose product is involved in AM-toxin synthesis and pathogenicity. Mol. Plant-Microbe Interact. 13:742-753.
18. Jones, J. D. G., and Dangl, J. L. 2006. The plant immune system. Nature 444:323-329.

19. Kodama, M., Wada, H., Otani, H., Kohmoto, K., and Kimura, Y. 1998. 3,5-DI-O-caffeoylquinic acid, an infection-inhibiting factor from Pyrus pyrifolia induced by infection with Alternaria alternata. Phytochemistry 47:371-373.

20. Lazniewska, J., Macioszek, V. K., Lawrence, C. B., and Kononowicz, A. K. 2010. Fight to the death: Arabidopsis thaliana defense response to fungal necrotrophic pathogens. Acta Physiol. Plant. 32:1-10.

21. Lipka, U., Fuchs, R., and Lipka, V. 2008. Arabidopsis non-host resistance to powdery mildews. Curr. Opin. Plant Biol. 11:404-411.

22. Lipka, V., Dittgen, J., Bednarek, P., Bhat, R., Wiermer, M., Stein, M., Landtag, J., Brandt, W., Rosahl, S., Scheel, D., Llorente, F., Molina, A., Parker, J., Somerville, S., and Schulze-Lefert, P. 2005. Pre- and postinvasion defenses both contribute to nonhost resistance in Arabidopsis. Science 310:1180-1183.

23. Loehrer, M., Langenbach, C., Goellner, K., Conrath, U., and Schaffrath, U. 2008. Characterization of nonhost resistance of Arabidopsis to Asian soybean rust. Mol. Plant-Microbe Interact. 21:1421-1430.

24. Maeda, K., Houjyou, Y., Komatsu, T., Hori, H., Kodaira, T., and Ishikawa, A. 2009. AGB1 and PMR5 contribute to PEN2-mediated preinvasion resistance to Magnaporthe oryzae in Arabidopsis thaliana. Mol. PlantMicrobe Interact. 22:1331-1340.

25. Mysore, K. S., and Ryu, C.-M. 2004. Nonhost resistance: how much do we know? Trends Plant Sci. 9:97-104.

26. Narusaka, Y., Narusaka, M., Seki, M., Ishida, J., Shinozaki, K., Nan, Y., Park, P., Shiraishi, T., and Kobayashi, M. 2005. Cytological and molecular analyses of non-host resistance of Arabidopsis thaliana to Alternaria alternata. Mol. Plant Pathol. 6:615-627.

27. Niks, R. E., and Marcel, R. C. 2008. Nonhost and basal resistance: how to explain specificity? New Phytol. 182:817-828.

28. Nishimura, S., and Kohmoto, K. 1983. Roles of toxins in pathogenesis. Pages 137-157 in: Toxins and Plant Pathogenesis. J. M. Daly and B. J. Deverall, eds. Academic Press, Sydney, Australia.

29. Nurnberger, T., and Lipka, V. 2005. Non-host resistance in plants: new insights into an old phenomenon. Mol. Plant Pathol. 6:335-345.

30. Otani, H., Kohmoto, K., Kodama, M., and Nishimura, S. 1991. Role of host-specific toxins in the pathogenesis of Alternaria alternata. Pages 139-149 in: Molecular Strategies of Pathogens and Host Plants. S. S. Patil, S. Ouchi, D. Mills, and C. Vance, eds. Springer, New York.

31. Shinogi, T., Suzuki, T., Kurihara, T., Narusaka, Y., and Park P. 2003. Microscopic detection of reactive oxygen species generation in the compatible and incompatible interactions of Alternaria alternata Japanese pear pathotype and host plants. J. Gen. Plant Pathol. 69:7-16.

32. Spassieva, S. D., Markham, J. E., and Hille, J. 2002. The plant disease resistance gene Asc-1 prevents disruption of sphingolipid metabolism during AAL-toxin-induced programmed cell death. Plant J. 32:561-572.

33. Stein, M., Dittgen, J., Sanchez-Rodriguez, C., Hou, B.-H., Molina, A., Schulze-Lefert, P., Lipka, V., and Somerville, S. 2006. Arabidopsis PEN3/PDR8, an ATP binding cassette transporter, contributes to nonhost resistance to inappropriate pathogens that enter by direct penetration. Plant Cell 18:731-746.

34. Suzuki, T., Shionogi, T., Narusaka, Y., and Park, P. 2003. Infection behavior of Alternaria alternata Japanese pear pathotype and localization of $1,3-\beta$-D-glucan in compatible and incompatible interactions between the pathogen and host plants. J. Gen. Plant Pathol. 69:91-100.

35. Ternes, P., Feussner, K., Werner, S., Lerche, J., Iven, T., Heilmann, I., Riezman, H., and Feussner, I. 2011. Disruption of the ceramide synthase LOH1 causes spontaneous cell death in Arabidopsis thaliana. New Phytol. 192:841-854.

36. Thordal-Christensen, H., Zhang, Z., Wei, Y., and Collinge, D. B. 1997. Subcellular localization of $\mathrm{H}_{2} \mathrm{O}_{2}$ in plants. $\mathrm{H}_{2} \mathrm{O}_{2}$ accumulation in papillae and hypersensitive response during the barley-powdery mildew interaction. Plant J. 11:1187-1194.

37. van der Biezen, E. A., Overduin, B., Kneppers, T. J. A., Mesbah, L. A., Nijkamp, H. J. J., and Hille, J. 1994. Molecular genetic characterisation of the Asc locus of tomato conferring resistance to the fungal pathogen Alternaria alternata f. sp. lycopersici. Euphytica 79:205-217.

38. Yamagishi, D., Akamatsu, H., Otani, H., and Kodama, M. 2006. Pathological evaluation of host-specific AAL-toxins and fumonisin mycotoxins produced by Alternaria and Fusarium species. J. Gen. Plant Pathol. 72:323-327. 